\title{
A Comparison by Subject: Monograph Acquisition, Publication, and Circulation
}

\author{
Mary E. Morris
}

Library collection development in the 1980s is characterized by increasing demands and decreasing resources. This article will examine efforts to monitor the allocation of collection development resources at one institution in North Carolina, Western Carolina University.

Since the writing of the Collection Development Policy for Hunter Library dated September 1, 1978, WCU's curriculum has expanded by 27 percent, while the library materials budget to support the curriculum has decreased by 40 percent (see Table 1).

TABLE 1

Growth of Curriculum and Library Materials Budget

\begin{tabular}{lccccc}
\hline & Degree Programs & Bachelor's & Master's & Sixth Year & Budget \\
\cline { 2 - 6 } Sept. 1978 & 67 & 58 & 26 & 5 & $\$ 652,073^{*}$ \\
Sept. 1980 & 85 & 70 & 34 & 8 & 392,299 \\
Difference & +18 & +12 & +8 & +3 & $-259,774$ \\
\hline
\end{tabular}

*Including Catch-Up Funds

According to Formula A of the 1975 ACRL Standards for College Libraries, 70,200 additional relevant printed volumes (or microform volume-equivalents) are required to support the twenty-three additional degrees, eighteen of which are new academic programs. However, Hunter Library purchased only 18,959 monograph volumes in $1978 / 79,8,919$ in $1979 / 80$, and 5,532 during 1980/81. We are acquiring less than 20 percent of academic publication.

Because of inflation and the growing proportion of the library materials budget obligated for serials, the rate of monograph acquisition was not expected to increase in 1981/82 despite the anticipated 30 percent increase in the budget. At the current rate of increase, serial obligations were expected to require 70 percent of the library materials budget if the budget were increased to $\$ 509,988$ and 91 percent if the budget remained at its 1980/81 level.

Spiraling inflation, off-campus programs, growing demand for print and non-print materials, as well as changing methods and trends in teaching and research, extend the demands on shrinking collection development resources. 
Fortunately, Hunter Library's present collection is relatively strong and well. balanced and use of materials already in the collection is growing. Inter-library cooperation and loans provide access to additional resources. Close cooperation between the faculty and the subject bibliographers facilitates optimal use of collection development resources.

\section{Collection Development Policy}

Hunter Library does not apportion library materials funds among the academic departments. While it is the prerogative of every faculty member to recommend particular books and periodicals, the primary responsibility for collection development in specific subject areas rests with the bibliographers to whom the subject areas have been assigned. Professional librarians at Hunter Library serve as subject bibliographers.

A written Collection Development Policy for Hunter Library defines the appropriate level of collecting in each Library of Congress classification area according to the academic programs supported by each subject area. The policy describes the clientele to be served and the kinds of programs and user needs supported by the collection. The policy provides subject bibliographers with guidelines for acquiring knowledge of the literature and of its use at this institu. tion.

In accordance with the Collection Development Policy, the bibliographers agree upon the ratio of serial and monograph expenditure and upon the percentage of available funds to be spent for monographs in each LC area. The following factors are among those considered:

- academic courses, faculty size and load, student enrollment, credit hours, graduate programs, degrees offered, new or expanding programs, off-campus programs, anticipated changes in the curriculum;

- strengths and weaknesses of present collections;

- actual use of materials based on circulation records, user surveys, and individual knowledge of usage;

- methods and trends in teaching, research, the publishing industry, and the book trade;

- quantity, rate, and pattern of publication and extent of the rate of obsolescence;

- comparative costs of materials including current rates of inflation;

- availability of materials in the marketplace;

- availability of materials through interlibrary cooperation.

The Acquisitions Librarian at Hunter Library is responsible for managing the library materials budget and for implementing the Collection Development Policy. These responsibilities include coordinating the efforts of subject bibliographers, providing data in each bibliographic area, and recommending appropriate rates of monograph acquisition in each subject area. 
As time permits, the Acquisitions Department compiles reports for the subject bibliographers, providing them with such data as current book prices and the number of books purchased in each bibiographic area. Data pertinent to analyzing and evaluating the collections are gathered throughout the year. Since July 1, 1980, Hunter Library's monthly departmental statistical reports have been coordinated according to the same sub-divisions of the classification system. Uniform statistical reporting provides linkage of basic acquisitions, cataloging, and circulation data until such time as an integrated automated system can provide complete interface. As a subscriber to Baker \& Taylor Company's Current Awareness Service, Hunter Library receives notice of academic publications and pertinent statistics in the company's Approval Program Management Information Reports. As a means of monitoring the percentages of the monograph budget assigned to each LC area, the Acquisitions Librarian uses such available data to conduct internal studies of collection development patterns.

\section{Data Gathered and Evaluated}

In a recent study the Acquisitions Librarian compared book acquisition, publication, and circulation rates in forty different subject groupings of the LC classes. Art (N) books, for example, accounting for 4.7 percent of the books purchased by Hunter Library from the 1979/80 monograph budget (259 of $5,546), 4.9$ percent of the academic books published during 1979/80 (1,442 of 29,404 ), and 3.9 percent of the books circulated by Hunter Library during JulyDecember of $1980(1,605$ of 41,218$)$. At an average price of $\$ 23.11,259$ art books required $\$ 6,000$ or 6 percent of the $\$ 100,000$ monograph budget.

Rates of acquisition, publication, and circulation were similar in most of the forty subject areas (see Table 2). However, publication percentages exceeded those of acquisition and circulation in several subject areas that are broader in scope than Western Carolina University's present curriculum, such as Military Science (U, V), Medical Sciences (R-RS, RV-RZ), and Business, Economics (HB-HJ). Technology, Engineering (T-TP, TS-TT), for example, accounted for 8.0 percent of academic publication, but only 3.6 percent of Hunter Library's circulation and 2.3 percent of Hunter Library's acquisition. Not all of the academic publication in the areas of Religion (BL-BX), Physics (QC), and Math, Computer Science (QA) is relevant to Western Carolina University's curriculum.

In several subjects that support well established areas of the curriculum, publication rates were exceeded by Hunter Library's circulation and acquisition rates. American History (E-F) for example, accounted for only 2.0 percent of academic publication but for 5.6 percent of circulation and 4.5 percent of acquisition. Circulation and acquisition percentages also exceeded publication percentages in Psychology (BF), History: General and Old World (C-D), Sociology (HM-HX), Education (L), Nursing (RT), and Home Economics (TX). 
A

B-BD, BH-BJ

$\mathrm{BF}$

BL-BX

C.D

E-F

G-GC

GF.GT

GV

$\mathrm{H}$

HA

HB.HJ

HM-HX

J

K

L

M

N

$P$

PA-PC, PQ

PD, PF, PG-PL, PT

PN

PE, PR

PS

PZ

Q

QA

QB

QC

QD

QE

QH.QR

R-RS, RV-RZ

RT

$\mathrm{S}$

T-TP, TS-TT

TR

TX

U, V

Z general works (reference)

philosophy

psychology

religion

history: general \& old world

history: America

geography

anthropology

physical education, recreation

social sciences, general

statistics

business, economics

sociology

political science

law

education

music

art

linguistics

foreign languages, romance

Germanic languages

lit. hist., theater, journalism

English, language \& literature

American literature

juvenile

general science

math, computer science

astronomy

physics

chemistry

geology

botany, biology

medical sciences

nursing

agriculture

technology, engineering

photography

home economics

military science

library science, publishing
22.97

18.98

19.06

13.68

18.54

16.17

20.79

17.03

13.63

19.33

19.33

17.66

16.64

17.54

19.95

14.22

18.44

23.11

18.45

17.60

13.12

16.25

18.58

13.99

7.13

22.17

25.83

20.73

33.84

39.20

27.51

26.54

18.63

13.44

19.29

27.18

20.32

14.87

17.89

16.35

*data incomplete or not available 
Publication, and Circulation by Subject

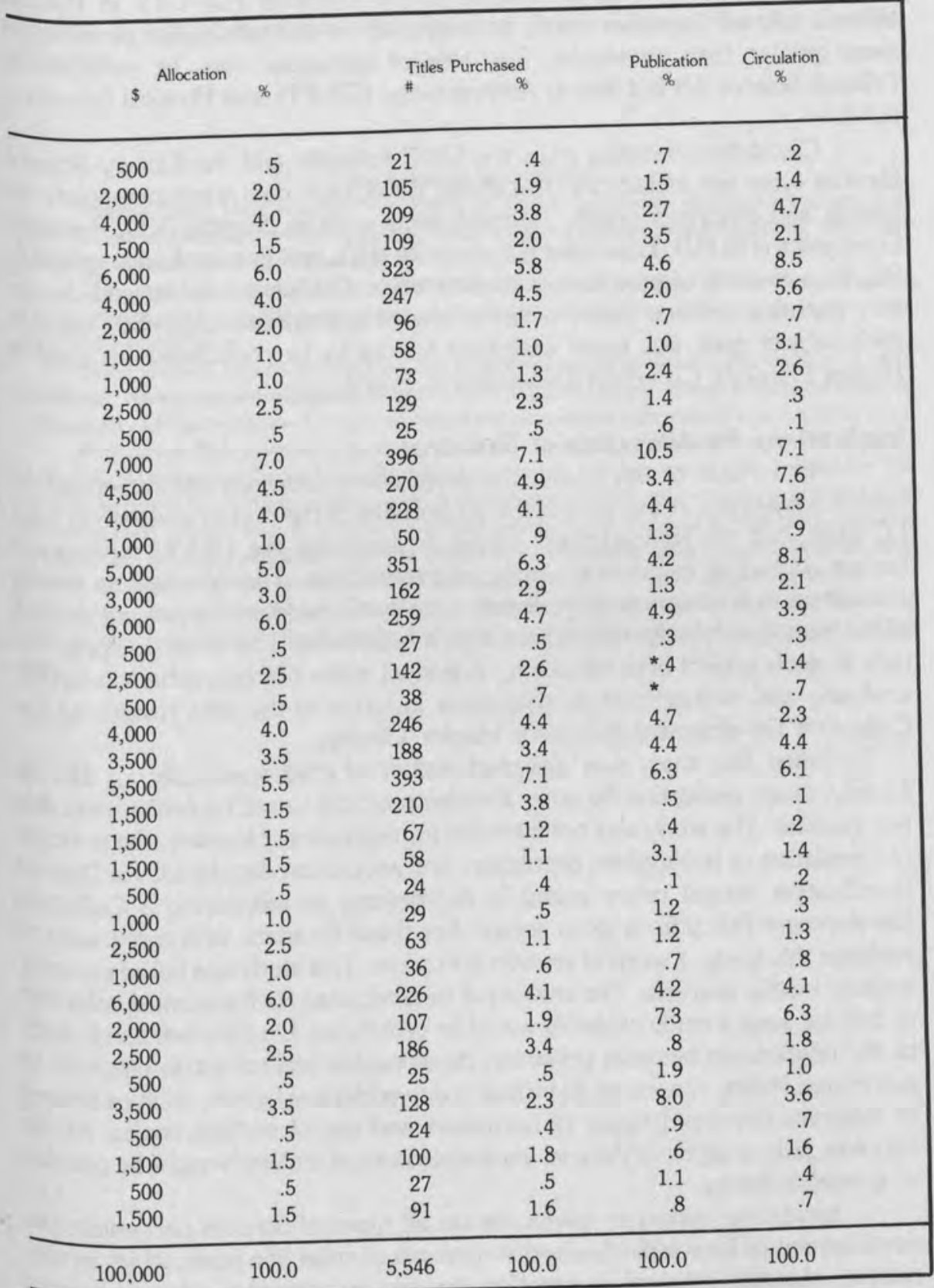


Acquisition rates in three areas need further scrutiny. Acquisition percentages were exceeded by both publication and circulation in Physical Education (GV). Both acquisition and publication percentages (which were equal) were exceeded by circulation in Anthropology (GF-GT). In Political Science $(\mathrm{J})$, on the other hand, both acquisition and publication percentages were greater than circulation. The rate of acquisition may be excessive in Political Science $(J)$ but low in Anthropology (GF-FT) and Physical Education (GV).

Circulation statistics from the UNC.Asheville and the Library Science libraries were not included in this study; publication data were incomplete for foreign and children's books. Affected areas such as Nursing (RT), Business, Economics (HB-HJ), Education (L), Juvenile (PZ), and Foreign Languages (PA. $\mathrm{PC}, \mathrm{PQ}$ ) also will require further consideration. Publication output and circulation statistics are two major determinants of appropriate acquisition rates in each subject area, but many additional factors to be considered are cited in Hunter Library's Collection Development Policy.

\section{Implications for Allocation of Resources}

As a result of this study, the Acquisitions Librarian recommended no further adjustment at this time in the proportions of the budget assigned to each LC area, and the bibliographers agreed to apportion the 1981/82 monograph budget according to currently assigned percentages. The correlations among acquisition, publication, and circulation rates confirmed that the present division of the monograph budget by subject area is reasonable. This study also provided data in each subject area for use by individual subject bibliographers in further analysing and evaluating their collections in terms of the 1981 revision of the Collection Development Policy for Hunter Library.

Since this study was designed and conducted specifically for Hunter Library, exact replication by other libraries probably would be neither desirable nor possible. The study was not intended for replication. However, the principle of correlation of publication, circulation, and acquisition data by LC (or Dewey) classification should prove useful in determining or monitoring a Collection Development Policy for a given library. For those librarians who might want to replicate this study, a word of caution is in order. This study was based primarily on data readily available. The amount of time required for the manual collection of data for such a study probably would be prohibitive. On the other hand, study of the relationship between collection development and collection usage in an automated library system could include many additional factors, such as the age of materials circulated, types of borrowers and use of multiple copies. At the opposite pole, analysis of internal unrecorded use of materials might be possible in a smaller library.

Increasing budgetary pressures on all types of libraries necessitate the development of local individualized statements of collection goals, which in turn require objective internal information for use in assessing progress toward 
achieving stated goals. In the final analysis, judgment, experience, and knowledge are indispensible to the development and assessment of each individual library collection.

\section{Mary E. Morris is Acquisitions Librarian at Hunter Library, Western Carolina} Univeristy.

\section{Data Sources and Notes}

Average Price: Data adapted from Baker \& Taylor Company's Approval Program, July 1979. June 1980, Management Information Report for all categories except Germanic languages and juvenile which were based on Bowker Annual for 1980.

Allocation: Monograph budget of $\$ 100,000$ for $1979 / 80$ apportioned by Library of Congress classification according to the percentages of the budget assigned for collection development in each bibliographic area.

Titles: Current allocations were divided by average prices to estimate the number of titles purchased. Allocations were converted from percentages of dollars to percentages of titles for comparison with percentages of books published and percentages circulated in each subject area.

Publication: Data adapted from Baker \& Taylor Company's Approval Program, July 1979. June 1980, Management Information Report by converting the number of titles included in the program to percentages in each subject area. Although Approval Program coverage of publication output in each subject area is generally comprehensive, Germanic and foreign languages and juveniles are generally excluded from the program. According to data adapted from Bowker Annual for 1980, juveniles accounted for 7 percent of total book title output for 1979 .

Circulation: Data adapted from Hunter Library's circulation statistics, July - December 1980 , by converting the number of books circulated to the percentages circulated in each subject area. 